\title{
The Relationship between Knee Flexor-Extensor Muscle Strength and Balance Ability in Elite Gymnasts
}

\author{
Jimnastik Sporcularnda Diz Fleksör-Ekstansör Kas Kuvvetinin \\ Denge ile İlişkisi
}

\author{
Aydın Balc1 ${ }^{1}$, Tuğba Kocahan², Bihter Akınoğlu ${ }^{3}$ \\ ${ }^{1}$ Sports Medicine Division, Yenimahalle Training and Research Hospital, Yildırım Beyazıt University, Ankara, Turkey \\ ${ }^{2}$ Sports Medicine Division, Directorate of Health Affairs, General Directorate of Sports, Ministry of Youth and Sports, Ankara, \\ Turkey \\ ${ }^{3}$ Department of Physical Therapy and Rehabilitation, Faculty of Health Sciences, Yıldırım Beyazıt University, Ankara, Turkey
}

\author{
A. Balcl \\ 0000-0002-9072-3397 \\ T. Kocahan iD \\ 0000-0002-0567-857X \\ B. Akınoğlu \\ 0000-0002-8214-7895 \\ Geliş Tarihi/Date Received: \\ 16.07.2019 \\ Kabul Tarihi/Date Accepted: \\ 12.11.2019 \\ Yayın Tarihi/Published Online \\ 27.03.2020

\section{Yazışma Adresi /} \\ Corresponding Author: \\ Aydın Balcı \\ Yıldırım Beyazıt Üniversitesi \\ Yenimahalle Eğitim Ve \\ Araştırma Hastanesi, Spor \\ Hekimliği, Ankara, Turkey \\ E-mail: \\ aydinbalci1985@hotmail.com
}

(C)2020 Türkiye Spor Hekimleri Derneği. Tüm hakları saklıdır.

\begin{abstract}
Objective: The aim of this study was to determine the relationship between balance skill and concentric and eccentric isokinetic knee muscle strength in elite gymnasts.

Materials and Methods: A total of 30 (17 males, 13 females) elite gymnasts were included in the study. Y-balance test, isokinetic concentric and eccentric muscle strength measurements were applied to the subjects on different days. Pearson correlation analysis was used to determine the relationship between isokinetic muscle strength and balance ability. The relationship between isokinetic muscle strength and total balance scores of each extremity was evaluated by simple linear regression analysis.

Results: Statistically significant, weak and moderate correlations were found between isokinetic muscle strength and balance ability $(r=0.36-0.66)$. As a result of simple linear regression analysis, significant relationships were found between concentric and eccentric isokinetic muscle strength of right and left knees, and total balance score (adjusted $R^{2}=0.16-0.41$ ).

Conclusion: Weak and moderate relationships between balance skill and isokinetic knee muscle strength was determined in elite gymnasts. It is concluded that knee joint muscle strength is related to balance ability. However, the level of relationship might vary according to the type of strength and balance exercises.

Keywords: Eccentric, isokinetic, concentric, $\mathrm{Y}$ balance test
\end{abstract}

ÖZ

Amaç: Çalışmanın amacı elit jimnastik sporcularında denge becerisi ile diz çevresi konsantrik ve eksantrik izokinetik kas kuvveti arasındaki ilişkiyi belirlemektir.

Gereç ve Yöntem: Çalışmaya 30 (17 erkek, 13 kadın) elit jimnastik sporcusu alındı. Katılımcılara farklı günlerde $Y$ Denge Testi, izokinetik konsantrik kas kuvveti ölçümü ve izokinetik eksantrik kas kuvveti ölçümü yapıldı. İzokinetik kas kuvveti ile denge becerisi arasındaki ilişkiyi belirlemek amacıyla Pearson korelasyon analizi kullanıldı. Her bir bacağın izokinetik kas kuvveti ile toplam denge skorları arasındaki ilişki basit doğrusal regresyon analizi ile değerlendirildi.

Bulgular: İzokinetik kas kuvveti ve denge becerisi arasında istatistiksel olarak anlamlı zayıf ve orta düzeyde korelasyonlar saptandı $(r=0.36-0.66)$. Basit doğrusal regresyon analizi sonucunda sağ ve sol diz konsantrik ve eksantrik izokinetik kas kuvveti ile toplam denge skoru arasında anlamlı ilişki bulundu (düzeltilmiş $R^{2}=0.16-0.41$ ). 
Sonuç: Elit jimnastik sporcularında denge becerisi ile diz çevresi izokinetik kas kuvveti arasında zayıf ve orta düzeyde ilişki saptandı. Çalışma sonucunda diz eklemi kas kuvvetinin denge becerisi ile ilişkili olduğu, ancak ilişki düzeyinin kuvvet ve denge egzersizinin türüne göre değişiklik gösterebileceği sonucuna varıldı.

Anahtar Sözcükler: Eksantrik, izokinetik, konsantrik, Y denge testi

Available at: http://journalofsportsmedicine.org and http://dx.doi.org/10.5152/tjsm.2020.178

Cite this article as: Balci A, Kocahan T, Akinoglu B. The relationship between knee flexor-extensor muscle strength and balance ability in elite gymnasts. Turk J Sports Med. 2020;55(3):214-21.

\section{GíRiş}

Jimnastik, Olimpiyatların en popüler yarışmalarından biridir. Zorluk derecesi yüksek hareketler barındırması nedeniyle esneklik, kuvvet, hız, denge ve branşa özgü antropometrik özelliklerin kombinasyonunu gerektiren bir branştır (1). Elit düzeyde sporcu olmak için erken yaşlardan başlayarak uzun yıllar düzenli ve yüksek şiddette antrenmanlar gerekir (2). Bu antrenmanların temelini kuvvet ve denge egzersizleri oluşturmaktadır $(3,4)$.

Denge ve kas kuvveti günlük yaşama ilişkin ve sportif aktivitelerin önemli bir bileşenidir ve benzer nörofizyolojik yapılar tarafından kontrol edilmektedir (5). Buna ek olarak literatürde "transfer etkisi" olarak tanımlanan, denge antrenmanlarının kuvvet üzerine dolaylı etkisi gösterilmiştir $(6,7)$. Denge ve kas kuvveti kaybında sportif performansın etkilendiği ve spor yaralanması riskinin arttığı bilinmektedir $(8,9)$. Geçmişte, sağlıklı çocuklarda kuvvet ve denge arasındaki ilişkiyi araştıran çalışmalar yapılmış ve bu iki parametre arasında düşük düzeyde korelasyon $(\mathrm{r}<0.40)$ saptanmıştır $(7,10,11)$. Yakın zamanda yapılan bir meta-analiz çalışmasında kuvvet ve denge parametrelerinin ilişkisi araştırılmış ve zayıf korelasyon gözlenmiştir (5). Bu çalışmalar sağlıklı ancak sporcu olmayan katılımcılarda yapılmıştır.

Sporcular ile sağlıklı sedanter bireylerin motor performansları arasında farklılıklar bulunmakta (12); bu nedenle daha önceki çalışmaların sporculardaki durumu tam olarak yansıtmadı̆̆ı düşünülmektedir. Bu çalışmaya elit jimnastik sporcuları dahil edildi ve hem konsantrik hem de eksantrik izokinetik kas kuvveti ölçümü yapıldı. Çalışma bu özellikleri nedeniyle öncekilerden farklılık göstermektedir. Bu çalışmanın amacı elit jimnastik sporcularında diz eklemi konsant- rik ve eksantrik izokinetik kas kuvveti değerleri ile Y denge testiyle değerlendirilen denge becerisi arasındaki ilişkiyi belirlemektir. Çalışmanın hipotezi kuvvet ve denge arasında güçlü ilişkinin olacağ şeklindedir.

\section{GEREÇ ve YÖNTEM}

\section{Katılımcilar}

Çalışmaya 30 (17 erkek, 13 kadın) elit jimnastik sporcusu alındı. Sporculara çalışma hakkında ayrıntılı bilgi verilerek, katılmak isteyenlerden ve yasal temsilcilerinden sözlü ve yazılı onay alındı. Katılımcıların hastalık ve yaralanma öyküsü sorgulandı, fizik muayeneleri bir spor hekimliği uzmanı tarafından yapıldı. Çalışmaya en az altı aydır herhangi bir spor yaralanması geçirmemiş olan, en az üç yıldır haftada en az beş gün ve en az iki saat jimnastik sporuna özel antrenman yapan sporcular alınd. Aktif problemi ve kas iskelet sistemi dizilim bozukluğu (ayak bileği pronasyonu, ayak bileği supinasyonu, genu varum, genu valgum, femoral anteversiyon) olanlar çalışmaya alınmadı. Çalışmanın etik kurul onayı Üniversite Etik Kurulundan alındı (2019/185:41).

\section{Çalışma Tasarımı}

Farklı günlerde katılımcıların Y denge testi, konsantrik ve eksantrik izokinetik kas kuvveti ölçümleri yapıldı. İlk gün katılımcıların yaralanma öyküleri sorgulandı ve fizik muayeneleri gerçekleştirildi. Bu muayenelerin ardından Y denge testi ile denge becerileri ölçüldü. Denge testinden 24 saat sonra konsantrik ve eksantrik izokinetik kas kuvveti ölçümleri yapıldı. Kuvvet ölçümleri aynı kas grubuna yapılacağı ve bu kas grubunun toparlanmasının standardize edilebilmesi için eksantrik kas kuvvet ölçümü konsantrik ölçümden 48 saat sonra gerçekleştirildi. 
Testler tüm katılımcılara aynı sıra ile ve günün aynı saatlerinde (09:00-12:00) uygulandı. Katılımcıların çalışma süresince antrenman yapmaları engellendi.

\section{$Y$ denge testi}

Denge ölçümleri için Star Excursion Balance Testin bir varyasyonu olan Y denge testi uygulandı. Bu testte katılımcılardan, hazırlanan platformun ortasında çıplak ayakla tek ayak üzerinde durmaları ve diğer ayak ile üç yönde [anterior, posteromedial (PM), posterolateral (PL)] dokunabilecekleri en uzak noktaya dokunmaları istendi. Ölçümler kaydedilmeden önce her bacak için birer deneme yaptırıldı ve ardından her yöne üç tekrar olacak şekilde denge testleri uygulandı. En yüksek değer o yöndeki denge skoru olarak kaydedildi. Her bacak için üç yöndeki denge skorları toplanarak total denge skorları bulundu. Bu sonuçlar sağ total denge skoru ve sol total denge skoru olarak kaydedildi.

\section{İzokinetik kas kuvveti ölçümü}

İzokinetik kas kuvveti ölçümleri IsoMed 2000。 (D\&R Ferstl GmbH, Hemau, Germany) izokinetik dinamometre kullanılarak yapıldı. Cihaza düzenli aralıklarla bakım yapılmakta olup, çalışma öncesinde kalibre edildi. Katılımcllar otururken alt ekstremiteleri cihazın kullanma kılavuzunda belirtildiği pozisyona getirildi. Ölçümlerden önce her açısal hızda üç tekrarlık deneme yapıldı. Katılımcilara egzersizleri maksimum hız ve kuvvette yapmaları söylendi. Konsantrik kas kuvveti ölçümleri için $60^{\circ} \mathrm{s}$ açısal hızda beş tekrarlı ve $180^{\circ}$ /s açısal hızda 15 tekrarlı diz fleksiyon ve ekstansiyon hareketi yaptırıldı. Eksantrik kas kuvveti ölçümleri için de, ilk ölçümden 48 saat sonra, aynı açısal hızlarda aynı tekrar sayılı diz fleksiyon ve ekstansiyon hareketi yaptırıldı. Elde edilen verilerin zirve tork (ZT) değerleri istatistiksel analizde kullanıldı.

\section{İstatistiksel analiz}

Çalışmanın istatistikleri SPSS 20.0 for Windows (Statistical Package for Social Sciences, Chicago, IL, USA) paket programı ile yapıldı. Elde edilen verilerin normal dağılıp dağılmadıklarının belirlenmesi için görsel olarak histogram ve olasılık grafikleri, analitik olarak Kolmogorov-Smirnov testi kullanıldı. Veriler ortalama \pm standart sapma olarak kaydedildi. İzokinetik kas kuvveti ile toplam denge skorları arasındaki ilişkiyi belirlemek amacıyla, tüm veriler normal dağıldığı için, Pearson korelasyon analizi kullanıldı. Bunun için $r=0-0.3$ ihmal edilebilir korelasyon; $r=0.31-0.50$ düşük düzeyde korelasyon; $r=0.51$ 0.70 orta düzeyde korelasyon; $r=0.71-0.90$ güçlü korelasyon; $r=0.91-1.00$ ise çok güçlü korelasyon olarak kabul edildi (13). Her bacağın toplam denge skoru ile zirve tork (ZT) değerleri $\left(60^{\circ} / \mathrm{s}\right.$ konsantrik ekstansiyon ve konsantrik fleksiyon, $180^{\circ} / \mathrm{s}$ konsantrik ekstansiyon ve konsantrik fleksiyon, $60^{\circ} \mathrm{s}$ eksantrik ekstansiyon ve eksantrik fleksiyon, $180^{\circ} / \mathrm{s}$ eksantrik ekstansiyon ve eksantrik fleksiyon için) arasındaki ilişki teker teker basit doğrusal regresyon analizi ile değerlendirildi. Katılımcı sayısının yetersizliği nedeniyle çoklu doğrusal regresyon analizi yapılamadl.

\section{BULGULAR}

Çalışmaya 17 erkek (\%56.7), 13 kadın (\%43.3) olmak üzere toplam 30 jimnastik sporcusu alındı. Katılımcıların yaş ortalaması 15.9 1.6 yıl, boy ortalaması $164.5 \pm 9.3 \mathrm{~cm}$, vücut ağırlığı ortalaması $54.0 \pm 9.4 \mathrm{~kg}$, beden kütle indeksleri ortalaması $19.9 \pm 2.1 \mathrm{~kg} / \mathrm{m}^{2}$ idi. Katılımcıların denge skorları ile konsantrik ve eksantrik kas kuvveti değerleri Tablo 1'de verilmektedir.

Her iki taraf denge skorları ile izokinetik kas kuvveti arasındaki ilişkiler Tablo 2'de gösterilmektedir. Buna göre hem sağ bacak denge ve kuvvet skorları arasinda ( $\mathrm{r}=0.43-0.66$ ) hem de sol bacak denge ve kuvvet skorları arasında $(r=0.36-0.65)$ düşük orta düzeyde ilişki bulundu $(\mathrm{p}<0.05)$. 
Tablo 1. Deneklerin Y denge ve izokinetik test sonuçları ve sağ-sol karşılaştırılması

\begin{tabular}{|c|c|c|c|}
\hline & Săg & Sol & $\mathbf{p}^{*}$ \\
\hline \multicolumn{4}{|l|}{ Y denge testi } \\
\hline Anterior & $68.2 \pm 9.9$ & $69.4 \pm 7.3$ & 0.289 \\
\hline Posteromedial & $108.7 \pm 11.1$ & $109.2 \pm 7.7$ & 0.689 \\
\hline Posterolateral & $106.7 \pm 9.7$ & $107.6 \pm 8.2$ & 0.346 \\
\hline Total skor & $283.6 \pm 28.9$ & $286.2 \pm 21.0$ & 0.363 \\
\hline \multicolumn{4}{|c|}{ İzokinetik konsantrik zirve tork } \\
\hline $60 \%$ s Ekstansiyon & $152.4 \pm 49.5$ & $153.8 \pm 51.7$ & 0.485 \\
\hline $60^{\circ} / \mathrm{s}$ Fleksiyon & $86.3 \pm 26.6$ & $85.3 \pm 24.6$ & 0.565 \\
\hline $180^{\circ} / \mathrm{s}$ Ekstansiyon & $121.1 \pm 41.9$ & $121.0 \pm 38.1$ & 0.956 \\
\hline $180^{\circ} /$ s Fleksiyon & $72.1 \pm 22.1$ & $70.4 \pm 19.4$ & 0.304 \\
\hline \multicolumn{4}{|c|}{ İokinetik eksantrik zirve tork } \\
\hline $60^{\circ} / \mathrm{s}$ Ekstansiyon & $177.5 \pm 59.6$ & $172.3 \pm 58.7$ & 0.352 \\
\hline $60 \%$ s Fleksiyon & $95.8 \pm 32.3$ & $91.2 \pm 30.6$ & 0.054 \\
\hline $180^{\circ} /$ s Ekstansiyon & $169.6 \pm 54.6$ & $163.9 \pm 45.4$ & 0.174 \\
\hline $180^{\circ} / \mathrm{s}$ Fleksiyon & $91.7 \pm 25.5$ & $94.9 \pm 24.9$ & 0.135 \\
\hline
\end{tabular}

Denge değerleri $\mathrm{cm}$; tork değerleri $\mathrm{N} / \mathrm{m}$ olarak; *: Paired samples $t$ test

Tablo 2. Her iki taraf denge skorları ile izokinetik kas kuvveti arasındaki ilişkiler

\begin{tabular}{|c|c|c|c|c|c|c|c|c|c|}
\hline \multicolumn{2}{|c|}{$\begin{array}{c}\text { Denge } \\
\text { skorları }\end{array}$} & $\begin{array}{l}\text { Kon. } 60^{\circ} / \mathrm{s} \\
\text { Ekstan. }\end{array}$ & $\begin{array}{l}\text { Kon. } 60^{\circ} / \mathrm{s} \\
\text { Flek. }\end{array}$ & $\begin{array}{l}\text { Kon.180 } / \mathbf{s} \\
\text { Ekstan. }\end{array}$ & $\begin{array}{l}\text { Kon.180 } \% \text { s } \\
\text { Flek. }\end{array}$ & $\begin{array}{l}\text { Ek.60\% } / \mathrm{s} \\
\text { Ekstan. }\end{array}$ & $\begin{array}{l}\text { Ek.60 } / \mathrm{s} \\
\text { Flek. }\end{array}$ & $\begin{array}{l}\text { Ek.180 }^{\circ} / \mathbf{s} \\
\text { Ekstan. }\end{array}$ & $\begin{array}{l}\text { Ek.180 }{ }^{\circ} / \mathrm{s} \\
\text { Flek. }\end{array}$ \\
\hline \multirow{2}{*}{$\begin{array}{l}\text { Ant. } \\
\text { sağ }\end{array}$} & $\mathrm{r}$ & 0.507 & 0.460 & 0.536 & 0.497 & 0.437 & 0.477 & 0.478 & 0.460 \\
\hline & $\mathrm{p}$ & 0.004 & 0.011 & 0.002 & 0.005 & 0.016 & 0.008 & 0.007 & 0.011 \\
\hline \multirow{2}{*}{$\begin{array}{l}\text { PM } \\
\text { sağ }\end{array}$} & $r$ & 0.574 & 0.547 & 0.588 & 0.514 & 0.433 & 0.478 & 0.444 & 0.433 \\
\hline & $\mathrm{p}$ & 0.001 & 0.002 & 0.001 & 0.004 & 0.017 & 0.008 & 0.014 & 0.017 \\
\hline \multirow{2}{*}{$\begin{array}{l}\text { PL } \\
\text { sağ }\end{array}$} & $r$ & 0.661 & 0.616 & 0.648 & 0.586 & 0.508 & 0.553 & 0.528 & 0.524 \\
\hline & $\mathrm{p}$ & $<0.001$ & $<0.001$ & $<0.001$ & 0.001 & 0.004 & 0.002 & 0.003 & 0.003 \\
\hline \multirow{2}{*}{$\begin{array}{l}\text { Total } \\
\text { sağ }\end{array}$} & $r$ & 0.616 & 0.574 & 0.627 & 0.564 & 0.487 & 0.533 & 0.512 & 0.500 \\
\hline & $\mathrm{p}$ & $<0.001$ & 0.001 & $<0.001$ & 0.001 & 0.006 & 0.002 & 0.004 & 0.005 \\
\hline \multirow{2}{*}{$\begin{array}{l}\text { Ant. } \\
\text { sol }\end{array}$} & $r$ & 0.521 & 0.374 & 0.459 & 0.363 & 0.406 & 0.436 & 0.410 & 0.478 \\
\hline & $\mathrm{p}$ & 0.003 & 0.042 & 0.011 & 0.049 & 0.026 & 0.016 & 0.024 & 0.008 \\
\hline \multirow{2}{*}{$\begin{array}{l}\text { PM } \\
\text { sol }\end{array}$} & $r$ & 0.630 & 0.513 & 0.648 & 0.516 & 0.366 & 0.474 & 0.404 & 0.483 \\
\hline & $\mathrm{p}$ & $<0.001$ & 0.004 & $<0.001$ & 0.003 & 0.047 & 0.008 & 0.027 & 0.007 \\
\hline \multirow{2}{*}{$\begin{array}{l}\text { PL } \\
\text { sol }\end{array}$} & $r$ & 0.618 & 0.557 & 0.616 & 0.487 & 0.417 & 0.444 & 0.459 & 0.489 \\
\hline & $\mathrm{p}$ & $<0.001$ & 0.001 & $<0.001$ & 0.006 & 0.022 & 0.014 & 0.011 & 0.006 \\
\hline \multirow{2}{*}{$\begin{array}{l}\text { Total } \\
\text { sol }\end{array}$} & $r$ & 0.653 & 0.535 & 0.637 & 0.505 & 0.438 & 0.498 & 0.470 & 0.534 \\
\hline & $\mathrm{p}$ & $<0.001$ & 0.002 & $<0.001$ & 0.004 & 0.016 & 0.005 & 0.009 & 0.002 \\
\hline
\end{tabular}

Ant: anterior, PM: posteromedial, PL: posterolateral, Kon: konsantrik, Ek: eksantrik, Ekstan: ekstansiyon, Flek: fleksiyon 
Her iki tarafın total denge skorları ile aynı taraf izokinetik kuvvet değerleri arasındaki ilişki basit doğrusal regresyon analizi ile değerlendirildi. Buna göre sağ izokinetik konsantrik kas kuvveti değerleri sağ total denge skorunun belirlenmesinde toplam varyansın \%29-36'sını; sağ izokinetik eksantrik kas kuvveti değerleri sağ total denge skorunun belirlenmesinde toplam varyansın \%21-26'sını; sol izokinetik konsantrik kas kuvveti değerleri sol total denge skorunun belirlenmesinde toplam varyansın \%23-41'ini; sol izokinetik eksantrik kas kuvveti değerleri sol total denge skorunun belirlenmesinde toplam varyansın \%16-26'sını açıklamaktadır (Tablo 3).

Tablo 3. İzokinetik zirve tork değerleri ve total denge skorları arasındaki basit regresyon analizi

\begin{tabular}{|c|c|c|c|c|c|c|c|c|c|c|}
\hline $\begin{array}{l}\text { BD } \\
(y)\end{array}$ & BzD (x) & $\mathbf{R S}$ & Kes. & SH & Beta & $\mathbf{t}$ & $\mathbf{p}$ & $\mathbf{R}^{2}$ & $\mathbf{R}^{2} \mathbf{d}$ & Formül \\
\hline \multirow{8}{*}{$\begin{array}{l}\text { Sağ } \\
\text { TDS }\end{array}$} & $\begin{array}{l}\text { Kon. } 60^{\circ} / \mathrm{s} \\
\text { Ekstan. }\end{array}$ & 228.800 & 0.360 & 0.870 & 0.616 & 4.135 & 0.001 & 0.379 & 0.357 & $y=228.800+(0.360) x$ \\
\hline & $\begin{array}{l}\text { Kon. } 60^{\circ} / \mathrm{s} \\
\text { Flek. }\end{array}$ & 229.796 & 0.624 & 0.168 & 0.574 & 3.713 & 0.001 & 0.330 & 0.306 & $y=229.796+(0.624) x$ \\
\hline & $\begin{array}{l}\text { Kon. } 180^{\circ} / \\
\text { s Ekstan. }\end{array}$ & 231.190 & 0.433 & 0.102 & 0.627 & 4.257 & 0.001 & 0.393 & 0.371 & $y=231.190+(0.433) x$ \\
\hline & $\begin{array}{c}\text { Kon. } 180^{\circ} / \\
\text { s Flek. }\end{array}$ & 230.329 & 0.739 & 0.204 & 0.564 & 3.618 & 0.001 & 0.319 & 0.294 & $y=230.329+(0.739) x$ \\
\hline & $\begin{array}{c}\text { Ek.60\% } 60^{\circ} \\
\text { Ekstan. }\end{array}$ & 241.700 & 0.236 & 0.080 & 0.487 & 2.947 & 0.006 & 0.237 & 0.210 & $y=241.700+(0.236) x$ \\
\hline & $\begin{array}{l}\text { Ek. } 60^{\circ} / \mathrm{s} \\
\text { Flek. }\end{array}$ & 237.885 & 0.477 & 0.143 & 0.533 & 3.332 & 0.002 & 0.284 & 0.258 & $y=237.885+(0.271) x$ \\
\hline & $\begin{array}{c}\text { Ek. } 180^{\circ} / \mathrm{s} \\
\text { Ekstan. }\end{array}$ & 237.661 & 0.271 & 0.086 & 0.512 & 3.151 & 0.004 & 0.262 & 0.235 & $y=237.661+(0.271) x$ \\
\hline & $\begin{array}{l}\text { Ek. } 180^{\circ} / \mathrm{s} \\
\quad \text { Flek. }\end{array}$ & 231.676 & 0.567 & 0.185 & 0.500 & 3.054 & 0.005 & 0.250 & 0.223 & $y=231.676+(0.567) x$ \\
\hline \multirow{8}{*}{$\begin{array}{c}\text { Sol } \\
\text { TDS }\end{array}$} & $\begin{array}{c}\text { Kon. } 60^{\circ} / \mathrm{s} \\
\text { Ekstan. }\end{array}$ & 245.341 & 0.266 & 0.058 & 0.653 & 4.558 & 0.001 & 0.426 & 0.405 & $y=245.341+(0.266) x$ \\
\hline & $\begin{array}{l}\text { Kon. } 60^{\circ} / \mathrm{s} \\
\text { Flek. }\end{array}$ & 247.155 & 0.458 & 0.137 & 0.535 & 3.352 & 0.002 & 0.286 & 0.261 & $y=247.155+(0.458) x$ \\
\hline & $\begin{array}{l}\text { Kon. } 180^{\circ} / \\
\text { s Ekstan. }\end{array}$ & 243.696 & 0.351 & 0.080 & 0.637 & 4.370 & 0.001 & 0.405 & 0.384 & $y=243.696+(0.351) x$ \\
\hline & $\begin{array}{c}\text { Kon. } 180^{\circ} / \\
\text { s Flek. }\end{array}$ & 247.565 & 0.549 & 0.177 & 0.505 & 3.097 & 0.004 & 0.255 & 0.229 & $y=247.565+(0.549) x$ \\
\hline & $\begin{array}{c}\text { Ek. } 60^{\circ} / \mathrm{s} \\
\text { Ekstan. }\end{array}$ & 259.179 & 0.157 & 0.061 & 0.438 & 2.577 & 0.016 & 0.192 & 0.163 & $y=259.179+(0.157) x$ \\
\hline & $\begin{array}{c}\text { Ek. } 60^{\circ} / \mathrm{s} \\
\text { Flek. }\end{array}$ & 255.025 & 0.342 & 0.112 & 0.498 & 3.042 & 0.005 & 0.248 & 0.221 & $y=255.025+(0.342) x$ \\
\hline & $\begin{array}{l}\text { Ek. } 180^{\circ} / \mathrm{s} \\
\text { Ekstan. }\end{array}$ & 250.503 & 0.218 & 0.077 & 0.470 & 2.817 & 0.009 & 0.221 & 0.193 & $y=250.503+(0.218) x$ \\
\hline & $\begin{array}{l}\text { Ek. } 180^{\circ} / \mathrm{s} \\
\text { Flek. }\end{array}$ & 243.365 & 0.451 & 0.135 & 0.534 & 3.341 & 0.002 & 0.285 & 0.259 & $y=243.365+(0.451) x$ \\
\hline
\end{tabular}

BD: bağımlı değişken, BzD: bağımsız değişken, TDS, total denge skoru RS: regresyon sabiti, Kes: kestirim, SH: standart hata, $R^{2}$ d: düzeltilmiş $R^{2}$ 


\section{TARTIŞMA}

$\mathrm{Bu}$ çalışma; elit jimnastik sporcularında, diz fleksör ve ekstansör kaslarının konsantrik ve ekstantrik izokinetik kas kuvvetleri ile denge arasındaki ilişkiyi değerlendirmektedir. Kas kuvveti ile denge becerilerinin benzer nörofizyolojik yapılar tarafından kontrol edilmesi nedeniyle bu iki parametre arasında güçlü ilişki olacağı çalışmanın hipotezidir (5).

Çalışma sonucunda elit jimnastik sporcularında diz çevresi konsantrik ve eksantrik izokinetik kas kuvveti ile denge becerisinin birbiri ile zayıf ve orta düzeyde ilişkili olduğu belirlendi. Muehlbaher ve ark.nın, 7-10 yaş arasındaki çocuklarda yaptığı çalışmada denge ve kas kuvveti arasında zayıf korelasyon ( $\mathrm{r}=0.54)$ olduğu gösterilmiștir (11). Genç erişkinlerde yapılan, Star Excursion Balance Test ile maksimal kuvvet ilişkisini ölçen bir çalışmada denge ve kuvvet arasında zayıf korelasyon olduğu saptanmıştır (14).

Kas kuvveti ile denge becerisi arasındaki zayıf ilişkinin, denge ve kuvvetten sorumlu nörofizyolojik yapılar benzer olmasına rağmen; bu yapıların dengenin kontrolü ile kuvvet üretimi sırasında göreve özgü yanıtlar vermesinden kaynaklandığı düşünülmektedir $(15,16)$. Denge ve kuvvet ile ilgili görevlerin yapılması sırasında spinal ve kortikospinal yapiların uyarılmasını inceleyen çalışmalarda izometrik ayak bileği egzersizlerine yanıt gözlenirken, denge için aynı yanıt gözlenmemiştir $(17,18)$. Gruber ve ark.nın "transfer etkisi"ni araștırdıkları çalışmalarında denge egzersizleri ile balistik kuvvet egzersizlerinin bazı kuvvet parametreleri üzerine etkisi karşılaştırılmıştır. Her iki egzersiz programının da maksimal kuvvet üzerine anlamlı pozitif etkisi saptanmıştır, ancak kas aktivasyonu ve spinal refleks uyarılması değerlerinde egzersiz grupları arasında farklılık bulunmuştur $(19,20)$. Bu sonuçlar denge ve kuvvet becerilerinin farklı mekanizmalarla ortaya çıktığı fikrini desteklemektedir.

Çalışmamızın sonuçlarının aksine kuvvet ve denge arasındaki korelasyonun güçlü olduğu çalışmalar da bulunmaktadır. Hammami ve ark.nın (21) yaptıkları çalışmada denge skorları ve sırt ekstansör kas kuvveti sonuçları arasında orta-yüksek düzeyde korelasyon belirlenmiștir $(r=0.49-0.79)$. Erişkin kadınlarda Y denge testi ve izometrik kas kuvveti ilişkisini ölçen bir çalışmada kalça ekstansör kasları ile denge skorları arasında ( $\mathrm{r}=0.70-0.75)$ ve diz fleksörleri ile denge skorları arasında ( $\mathrm{r}=0.71-0.83)$ güçlü korelasyon saptanmıștır (22). İzometrik kas kuvveti ile denge arasındaki ilişkiyi 6-10 yaşları arasında 90 erkek çocuğunda inceleyen bir çalışmada katılımcıların 11 farklı kas grubunun izometrik kas kuvveti ölçülmüş ve dinamik denge ölçümleri ile karşılaştırılmıștır. Katılımcıların alt ekstremite ve gövde kas gruplarının denge ile ilişkisinin orta-yüksek düzeyde olduğu, üst ekstremite kas grupları ile ilişkinin zayıf olduğu belirlenmiştir (23). Bu çalışmanın kısıtlılıklarında izometrik kas kuvveti ölçümü yerine daha güvenilir olan izokinetik kas kuvveti ölçümünün yapılmasının daha doğru olacağı bildirilmiștir (23). Çalışmamızda izokinetik kas kuvveti ölçümü yapılması çalışmanın gücünü arttırmaktadır.

Kuvvet ve denge ilișkisinin literatürdeki çalışmalarda farklı olması çeşitli mekanizmalarla açıklanmaktadır. Denge ve kuvvet ölçüm yöntemlerindeki farklılıkların bu çelişkinin bir nedeni olduğu düşünülmektedir (5). Ambegaonkar et al.in yaptıkları çalışmada katılımcıların kalça kas kuvvetleri ile Star Excursion Balance Test değerleri arasında anlamlı korelasyon bulunurken, kor endüransları ile denge arasında ilişki saptanmamıştır (24). Çalışmamızın sonuçlarına bakıldığında konsantrik kas kuvveti ile denge ilişkisinin eksantrik kas kuvvetine göre daha yüksek olduğu görülmektedir ve bu sonuç korelasyonun ölçüm yöntemine göre değiştiği fikri ile uyumludur.

Literatürdeki farklı sonuçların bir başka olası nedeninin yaptırılan egzersizlerin zorluk derecesi olduğu düşünülmektedir. Günlük fiziksel aktivite için yeterli kuvvet ve denge beceri kontrolünün göreceli olarak non-spesifik olduğu ve birbirinden etkilendiği; buna karşın spora özgü aktivitelerdeki becerilerin daha karmaşık beceriler gerektirdiği bilinmektedir (25-27). Bu durumda, temel kuvvet ve denge egzersizlerinin arasında güçlü ilişki olabileceği; bunun aksine egzersizler spesifik bir hal aldığında ise ilişkinin 
azalabileceği fikri ortaya çıkmaktadır. Son olarak kuvvet ve denge ölçümlerinin sirkadyen ritimden etkilendiği, akşam saatlerinde yapılan kuvvet ölçümlerinin sabaha göre yaklaşık \%10 daha iyi (28), denge ölçümlerinin ise sabah yapılan testlerde daha iyi olduğu gösterilmiştir (29). Bu da çalışmalar arasındaki farklı sonuçların bir nedeni olarak kabul edilebilmektedir. $\mathrm{Bu}$ çalışmada sirkadyen ritmin sonuçlara etkisinin standardizasyonu için tüm ölçümler sabah 09:00-12:00 arasında yapıldı.

Katılımcı sayısının az olması nedeniyle kadınerkek katılımcıların ayrı ayrı değerlendirilmesi ve kuvvet parametrelerinin denge ile ilişkisinin çoklu doğrusal regresyon ile analizi mümkün olmamıștır. Bunun yanında çalıșmanın kesitsel bir çalışma olması neden-sonuç ilişkisini göstermemektedir. $\mathrm{Bu}$ durumlar çalışmanın kısıtlılıkları olarak kabul edilebilir. Buna karşın, çalışmanın elit jimnastik sporcularında yapılması ve katılımcıların hem konsantrik hem eksantrik izokinetik kas kuvveti ölçümlerinin yapılmıș olması çalıșmayı literatürdeki benzerlerinden farklı kılmaktadır. Sonuç olarak çalışmada değerlendirilen kuvvet ve denge parametreleri arasında istatistiksel olarak anlaml, zayıf ve orta düzeyde korelasyon saptandı. Bu çalışmanın bulguları ve literatür bilgisinin ışığında kuvvet ve denge becerisi arasında bir ilişkinin bulunduğu, ancak bu ilişkinin egzersizin türü ile değişiklik gösterebildiği sonucuna ulaşılmaktadır.

\section{KAYNAKLAR}

1. Carrick FR, Oggero E, Pagnacco G, et al. Posturographic testing and motor learning predictability in gymnasts. Disabil Rehabil. 2007;29(24):1881-9.

2. Ericsson KA, Krampe RT, Tesch-Römer C. The role of deliberate practice in the acquisition of expert performance. Psychol Rev. 1993;100(3):363-406.

3. Cohen SB, Whiting WC, McLaine AJ. Implementation of balance training in a gymnast's conditioning program. Strength Cond J. 2002;24(2):60-7.

4. Jemni M, Sands WA, Friemel F, et al. Any effect of gymnastics training on upper-body and lower-body aerobic and power components in national and international male gymnasts? J Strength Cond Res. 2006;20(4):899-907.

5. Muehlbauer T, Gollhofer A, Granacher U. Associations between measures of balance and lower-extremity muscle strength/power in healthy individuals across the lifespan: a systematic review and meta-analysis. Sports Med. 2015;45(12):1671-92.

6. Granacher U, Gruber M, Gollhofer A. Resistance training and neuromuscular performance in seniors. Int $J$ Sports Med. 2009;30(9):652-7.

7. Granacher U, Gollhofer A, Kriemler S. Effects of balance training on postural sway, leg extensor strength, and jumping height in adolescents. Res Q Exerc Sport. 2010;81(3):245-51.

8. Rössler R, Donath L, Verhagen E, et al. Exercise-based injury prevention in child and adolescent sport: a systematic review and meta-analysis. Sports Med. 2014;44(12):1733-48.

9. Hrysomallis C. Balance ability and athletic performance. Sports Med. 2011;41(3):221-32.

10. Granacher $\mathrm{U}$, Gollhofer A. Is there an association between variables of postural control and strength in adolescents? J Strength Cond Res. 2011;25(6):1718-25.

11. Muehlbauer T, Besemer C, Wehrle A, et al. Relationship between strength, balance and mobility in children aged 7-10 years. Gait Posture. 2013;37(1):108-12.

12. McManus AM, Armstrong N. Physiology of elite young female athletes.Med Sports Sci. 2011;56:23-46.

13. Mukaka MM. Statistics corner: a guide to appropriate use of correlation coefficient in medical research. $M a-$ lawi Med J. 2012;24(3):69-71.

14. Hesari AF, Maoud G, Ortakand SM, et al. The relationship between star excursion balance test and lower extremity strength, range of motion and anthropometric characteristics. Med Sportiva. 2013;17(1):24-8.

15. Schubert M, Beck S, Taube $\mathrm{W}$, et al. Balance training and ballistic strength training are associated with task-specific corticospinal adaptations. Eur J Neurosci. 2008;27(8):2007-18.

16. Beck S, Taube W, Gruber M, et al. Task-specific changes in motor evoked potentials of lower limb muscles after different training interventions. Brain Res. 2007;1179:51-60.

17. Morita H, Olivier E, Baumgarten J, et al. Differential changes in corticospinal and Ia input to tibialis anterior and soleus motor neurones during voluntary contraction in man. Acta Physiol Scand. 2000;170(1):65-76.

18. Taube W, Schubert M, Gruber M, et al. Direct corticospinal pathways contribute to neuromuscular control of perturbed stance. J Appl Physiol (1985). 2006;101(2):420-9.

19. Gruber M, Gruber SB, Taube W, et al. Differential effects of ballistic versus sensorimotor training on rate of force development and neural activation in humans. J Strength Cond Res. 2007;21(1): 274-82.

20. Gruber M, Taube W, Gollhofer A, et al. Trainingspecific adaptations of $\mathrm{H}$-and stretch reflexes in human soleus muscle. J Motor Behav. 2007;39(1):68-78.

21. Hammami R, Chaouachi A, Makhlouf I, et al. Associations between balance and muscle strength, power per- 
formance in male youth athletes of different maturity status. Pediatr Exerc Sci. 2016;28(4):521-34.

22. Lee DK, Kim GM, Ha SM, et al. Correlation of the Ybalance test with lower-limb strength of adult women. J Phys Ther Sci. 2014;26(5):641-3.

23. Ibrahim AI, Muaidi QI, Abdelsalam MS, et al. Association of postural balance and isometric muscle strength in early- and middle-school-age boys. J Manipulative Physiol Ther. 2013;36(9):633-43.

24. Ambegaonkar JP, Mettinger LM, Caswell SV, et al. Relationships between core endurance, hip strength, and balance in collegiate female athletes. Int J Sports Phys Ther. 2014;9(5):604-16.

25. Kovacs AJ, Mühlbauer T, Shea $\mathrm{CH}$. The coding and effector transfer of movement sequences. J Exp Psychol Hum Percept Perform. 2009;35(2):390-407.
26. Muehlbauer T, Panzer S, Shea CH. The transfer of movement sequences: effects of decreased and increased load. Q J Exp Psychol (Hove). 2007;60(6):770-8.

27. Hikosaka 0 , Nakahara H, Rand MK, et al. Parallel neural networks for learning sequential procedures. Trends Neurosci. 1999;22(10):464-71.

28. Guette M, Gondin J, Martin A. Time-of-day effect on the torque and neuromuscular properties of dominant and non-dominant quadriceps femoris. Chronobiol Int. 2005;22(3):541-58.

29. Gribble PA, Hertel J, Denegar CR. Chronic ankle instability and fatigue create proximal joint alterations during performance of the Star Excursion Balance Test. Int J Sports Med. 2007;28(3): 236-42. 